\title{
Ecosistema prehispánico y circulación del espacio, la evidencia en grabados zoomorfos del sitio Alto de La Guitarra, valle de Moche, Virú.
}

\section{ModPrehispanic ecosystem and circulation of space, evidence in engravings zoomorfos of Alto de La Guitarra, Moche valley, Virú.}

\author{
Daniel Castillo Benitez', María Susana Barrau²
}

\section{RESUMEN}

En 2010 completamos el primer inventario del paisaje natural y cultural del sitio arqueológico Alto de la Guitarra, ubicado en el valle de Moche, departamento La Libertad, Perú. Después de 70 años de contribuciones parciales, en particular de Castillo (2000) y Campana (2004a; 2004b; 2006a y b), logramos desarrollar una nueva estrategia para realizar las actividades de investigación en un formato holístico (Castillo y Barrau 2010). Por consiguiente, se reunió un corpus de información ambiental y cultural del sitio, que incluyó el registro de 401 soportes con grabados rupestres, así como estructuras en superficie y vías de comunicación. Al sitio en su conjunto se lo considera una gran encrucijada de caminos, ya que senderos lo unen al norte con los valles de Moche y Chicama, al este con la serranía de Carabamba, y al sur con el valle de Virú. Por otro lado, el Alto de la Guitarra es ampliamente conocido por la concentración y excepcionalidad de los petroglifos, testimonios que permiten definirlo como un santuario de arte rupestre al aire libre. En este artículo presentamos un conjunto de cuatro grabados rupestres de imágenes zoomorfas, que ciertamente representan el ecosistema prehispánico.

Palabras clave: Petroglifos-Alto de la Guitarra-Valle de Moche-Perú

\begin{abstract}
In 2010 we completed the first inventory of the natural environment and cultural landscape of the Alto de la Guitarra archaeological site in the Moche valley, La Libertad Department, Perú. After 70 years of partial contributions, in particular from Castillo (2000) and Campana (2004a; 2004b; 2006), we were able to develop a new strategy for carrying out researching activities in a holistic format (Castillo and Barrau 2010). Therefore, a corpus of environmental and cultural aspects of the site was gathered, involving the recording of 401 boulders with art engravings, together with associated surface structures and main communication pathways. The whole site is considered a major crossroad of paths since walking trails are connecting to the north with the Moche and Chicama valley, to the east with the Serranía de Carabamba, and to the south with the Virú valley. On the other hand, the variety, concentration and exceptional nature of the petroglyphs in Alto de la Guitarra is widely recognized, attributes that allow us to define it as an open air rock art sanctuary. In this article we present a set of four rock art engravings corresponding to zoomorphic images that do represent the prehispanic.
\end{abstract}

Keywords: Petroglyphs-Alto de la Guitarra-Moche Valley-Peru

'Arqueólogo. Instituto de Investigación de Arqueología y Antropología “Kuélap” de la Universidad Nacional Toribio Rodríguez de Mendoza
deAmazonas. Correo electrónico: daniel.castillo@untrm.edu.pe.

${ }^{2}$ Lic. En Ciencias Antropológicas, Universidad de Buenos Aires. Correo electrónico: susanabarrau@hotmail.com 


\section{INTRODUCCIÓN}

El Alto de la Guitarra, verdadero santuario al aire libre de arte rupestre, es un sitio arqueológico que suscitó el interés de viajeros e investigadores que visitaron, registraron y documentaron los bienes culturales existentes, un contexto en que destaca la labor realizada por Castillo (2000) y Campana (2004a y b; 2006 a y b; 2013). Durante más de 60 años el conocimiento del sitio fue parcial, debido tanto a factores técnicos y metodológicos, como a las condiciones inherentes al lugar, ya que limitaron el tiempo dedicado a los estudios in situ, basta mencionar el aislamiento respecto de centros poblados, la ausencia de agua, e insolación y reverberación de los rayos solares en los sedimentos y rocas. A fines de 2006, y en consonancia con la realización del II SINAR en Trujillo, se conformó un equipo de investigación interdisciplinario, apoyado por el Museo Max Díaz Díaz, que diseñó el proyecto "Base de Datos Digital del Arte Rupestre de los Departamentos de La Libertad y Cajamarca, Perú". El objetivo básico fue aplicar al ámbito de los estudios rupestres los avances verificados en fotografía digital, la disponibilidad de equipos de iluminación portátil, y el acceso al tratamiento de imágenes a través de los programas Photoshop e Image J. DStretch, que permiten rescatar figuras que a simple vista ya no se observan. En este sentido, durante 2007/08 se generó un abordaje holístico para las investigaciones sistemáticas del arte rupestre en los Departamentos de La Libertad y Cajamarca, al tiempo que se intensificaron los estudios de campo, y avanzó en la digitalización de archivos propios y de terceros, en la conformación de un corpus de referencia organizado. Este enfoque, y la aplicación del concepto de inventario como herramienta heurística, permitió llevar a término el primer inventario general de bienes culturales en el Alto de la Guitarra (Castillo y Barrau, 2014), y en la cuenca del río Virú (Castillo y Barrau 2016).

\section{EL INVENTARIO DEL ALTO DE LA GUITARRA}

En el año 2010 realizamos en primer inventario de bienes culturales en el sitio, identificando las siguientes estructuras: una muralla, caminos, sendas, muros de piedra destinados a operar como dique/encausamiento del flujo de agua, 24 recintos de planta de piedra, algunos con espacios anexos de forma ortogonal, nivelados y limpiados, que corresponden al negativo de abrigos levantados con material perecedero. En definitiva, el Alto de la Guitarra carece de arquitectura monumental o construcciones de adobe, mientras que las estructuras mencionadas evidencian que los antiguos constructores tenían un amplio conocimiento de las áreas comprometidas en el sistema de drenaje de la quebrada. Además, al evaluar la data sobre muros colapsados determinamos que se debieron a la acción destructiva del fenómeno del Niño, que en ciertas oportunidades cobró una magnitud excepcional. Respecto a los materiales líticos o cerámicos en superficie, incluimos deshechos de talla junto a la muralla y alfarería que pertenece a los grupos Cupisnique, Salinar, Moche, Wari Santa, Chimú y Chimú-Inca, destacando la ausencia de alfarería Virú en el lugar.

Además, a la fecha registramos y documentamos 401 soportes con grabados rupestres, en su mayoría grandes bloques de granodiorita. La gran concentración, variabilidad, y excepcionalidad de soportes y grabados rupestres, incluso con estructuras asociadas, se ubica sobre la unión/tinku de los faldeos de los cerros tutelares, conformando un gran paisaje ritual. El carácter de excepcionalidad aludido responde a que se trata de expresiones rupestres únicas en su tipo, sea en el contexto de la producción rupestre, como en otros soportes, cerámica, hueso, concha, etc.

Por otra parte, cabe destacar que se empleó la técnica de borrado de imágenes (Campana 2006b, 19) a fin de regrabar un mismo motivo, con la clara intención de poner nuevamente en acto lo representado, y en otros casos, para ejecutar un repertorio acorde al sistema de creencias vigente, un procedimiento que también registramos en el valle de Virú (Castillo y Barrau 2016, 107-108).

\section{CONDICIONES DE SITIO Y POSICION DEL ALTO DE LA GUITARRA}

El Alto de la Guitarra es un sitio arqueológico ubicado en la costa norte peruana, en la divisoria de aguas de las cuencas de los ríos Moche y Virú, en las coordenadas 9099028 norte y 0740343 este, a una altitud promedio de $827 \mathrm{msnm}$. Este ámbito pertenece a la unidad de valles y quebradas tributarias del flanco occidental de los Andes, presenta una formación ecológica Matorral Desértico PreMontano, un clima árido y semicálido, con gran amplitud térmica, precipitaciones que fluctúan entre 50 y $200 \mathrm{~mm}$ anuales, y vientos predominantes del sector sur(ONERS, 1973).

El sitio ocupa una encrucijada de caminos que hacia el norte lo conectan con el sector medio del valle de Moche y vías que conducen al valle de Chicama, al este con la meseta de Carabamba y al sur con el sector medio del valle de Virú. Se trata de un espacio regional estructurado en base a una amplia red de 
comunicación entre grupos socio-culturales costeños y serranos, que interactuaron generando circuitos de intercambio de bienes e información, al tiempo que construían territorios de extensión variable, según el período temporal que consideremos. En este sentido, el arte rupestre constituye el marcador espaciotemporal y contextual a rastrear, registrar y documentar (Castillo y Barrau 2014, 313), ya que refleja y jalonea los avances y retrocesos de estas sociedades en el acceso efectivo a las nacientes de los cursos de agua costeños, una dinámica que en líneas generales explica el proceso cultural verificado a nivel regional.

En la búsqueda de la intencionalidad subyacente a la elección y construcción del sitio, más allá de la ponderación de las vías de comunicación o la disponibilidad de un recurso como los grandes bloques de granodiorita usados para la ejecución de los grabados rupestres, recurrimos en el análisis al concepto de dualidad, comprendido como una oposición complementaria, el principio organizador del sistema de creencias andino, de gran profundidad y continuidad temporal (Burger y Salazar Burger 1994). Así planteamos que el Alto de la Guitarra se extiende a partir de la unión/tinku de las cuencas de los ríos Moche y Virú, de las quebradas Alto de Guitarras y Las Guitarras, de los faldeos de los cerros tutelares que limitan el área, Alto de Guitarras al este y Guitarras al oeste, espacio atravesado por un curso de agua sinuoso que recorre $1250 \mathrm{~m}$ y se extiende, al igual que el sitio arqueológico, hasta la unión/tinku con el río Salinas, lugar señalado por una elevación baja que presenta en la cima al soporte rocoso 371 , completamente aislado y de gran tamaño: 3,50 x 2,70 $\mathrm{x}$ 1,40 $\mathrm{m}$. El mismo presenta grabados rupestres en todas las caras, incluso la superficial, que además exhibe una depresión/paccha destinada a contener agua y reflejar el cielo, un marcador espacio-cronocontextual notable.

\section{E COS I S T E M A P R E I S PÁ N I C O, CIRCULACIÓN Y ARTE RUPESTRE}

La mirada holística del área estudiada se enriquece al ponderar la reconstrucción etnohistórica de María Rostworowski (1981), que trata sobre los recursos naturales renovables de la costa durante los siglos XVI y XVII. Esta investigación combina aspectos medio ambientales, actividades económicas y prácticas socio-culturales, al tiempo que describe un espacio de lagunas pesqueras próximas al litoral, ciénagas cubiertas de totorales o juncales y formaciones de lomas, un terreno de caza y pastoreo que aprovecharon sociedades costeñas y serranas. El panorama se completa con bosques, salinas y pesca, una actividad que fomentó la especialización de grupos pescadores en el intercambio de pescado seco con los pueblos serranos. Al contrastar estos datos con el corpus del arte rupestre registrado y documentado en el Alto de la Guitarra, verificamos que las expresiones estudiadas construyen una narración que se condice con la información brindada por la autora, multiplicidad de aves (figura 1), mamíferos (figura 2), peces (figura 3), y otros, sumado a motivos que apuntan a la circulación de adoraciones entre sociedades costeñas y serranas (figura 4). Además, en los meses de junio a octubre la zona presenta una ecología de lomas, fenómeno que constatamos en dos ocasiones. Un manto de neblina denso asciende desde el valle de Moche y cubre el sitio, generando una garúa inmediata y fuerte que repercute en la vegetación y la presencia de fauna, un fenómeno que convirtió al lugar en un paraíso estacional para cazadores y recolectores, que también aprovecharon la presencia de caracoles terrestres para complementar la ingesta de proteínas, actividad puesta en evidencia por la erosión eólica, que dejó al descubierto acumulaciones de restos junto al soporte 380 y los recintos 20 y 21 del inventario.

En este artículo presentamos 4 motivos rupestres que se corresponden con el tema tratado y el número de imágenes aceptadas por los editores. En lo referente a las aves, la elección recayó sobre una garza grabada en el soporte 279 , de $30 \times 15 \mathrm{~cm}$, percutida con un surco promedio de $8 \mathrm{~mm}$. Una representación de grandes dimensiones corresponde al oso de anteojos o andino, soporte 127 (figura 2), que se observó y cazó en el Alto de la Guitarra hasta mediados del siglo pasado. Se realizó mediante la técnica de percutido, con un ancho de surco promedio de $10 \mathrm{~mm}$. El soporte 178 exhibe el motivo de un pez grabado de 40 x $70 \mathrm{~cm}$, trabajado con la técnica percutido, presentando un surco promedio de $7 \mathrm{~mm}$. Por último, la figura 4 corresponde a una paloma grabada en el soporte 12 , de $33 \times 15 \mathrm{~cm}$, ejecutada con la técnica de percutido y un surco de $5 \mathrm{~mm}$. Esta representación entendemos que podría representar la vigencia del relato sobre la hija menor de Pachacámac, que cuando iba a ser violada por Cuniraya se transformó en paloma, y su madre UrpayHuachac pasó a conocerse como la que pare palomas, diosa marina y costeña que aparece integrando el panteón de huacas serranas, y se la representaba bajo la forma de una palomita de hueso (Rostworowski de Diez Canseco, 2007:84). Esta autora hace hincapié en el rol del intercambio de pescado seco por productos serranos como el espacio de circulación de estas adoraciones, y es un rastro que seguimos a través de la producción rupestre. 


\section{CONCLUSIONES}

En síntesis, el Alto de la Guitarra puede concebirse como un santuario de arte rupestre al aire libre, un espacio circulado, construido, ritualizado y sagrado, que presenta límites precisos. Las expresiones rupestres en el sitio construyen una narración estrechamente conectada con la provisión de recursos, básicamente del agua, la caza, recolección, agricultura o pesca, en un medio similar al descripto por Rostworowski (1981). Las ceremonias y actividades rituales se organizaron en función de la estacionalidad de estos recursos, y giraron en torno de la reproducción de los grupos sociales que recorrieron o peregrinaron al sitio desde tiempos precerámicos.

A partir del período Arcaico Final apreciamos que El Alto de la Guitarra funcionó como un Centro Ceremonial Vacío, siguiendo la conceptualización de Silverman (1988) para Cahuachi, o sea que mantuvo una población estable mínima, y en forma cíclica, una vez alcanzado el tiempo del rito, se llenaba de peregrinos que interrumpían el ciclo de actividades profanas y se adentraban en la esfera de lo sagrado, para luego regresar a su lugar de origen una vez concluidas las ceremonias y ritos. En este contexto, el ciclo ceremonial iniciaba con ritos de agradecimiento y propiciatorios a comienzos de junio, antes del solsticio de invierno, al tiempo de la aparición de las Pléyades. Calancha (1974) hace referencia a las Cabrillas, que llamaban Collca y los yungas Fur, y por ellas contaban los años, es decir, fijaban el reinicio del calendario agrícola, que era la base del calendario ceremonial. Además, en el manuscrito de Huarochirí (Taylor 2008, 122-123) se destaca un aspecto premonitorio en la aparición de las Cabrillas, los informantes relatan que si la gente las veía asomar todas grandes sería un año de fertilidad, mientras que si las contemplaban pequeñas de seguro habría mucho sufrimiento. Es probable que las actividades ceremoniales y procesiones se repitieran durante la apertura de la tierra y en ocasión de la siembra y cosecha.

\section{REFERENCIAS BIBLIOGRÁFICAS}

Burger, R. y Salazar Burger, L. 1994, La organización dual en el ceremonial andino temprano: un repaso comparativo. En L. Millones y Y. Onuki (comp) El mundo ceremonial andino. Lima, pp 97-116.

Calancha, A. 1974, Crónica moralizadora del Orden de San Agustín en el Peru, con sucesos Egenplares en esta monarquia. Lima:
Ignacio Prado Pastor.

Campana C. $2004^{\mathrm{a}}$, La sal, el poder y los petroglifos del Alto de las Guitarras. Lima: Universidad Nacional Federico Villarreal.

Campana C. 2004b, "Alto de las Guitarras"; petroglifos, caminos, sal y poder. Lima, Primer Encuentro Peruano de Arte Rupestre.

Campana C. 2006 ${ }^{\mathrm{a}}$, La memoria del tiempo: imágenes del Alto de Las Guitarras. En: Tiempos. V. 1, pp. 7-34.

Campana C. 2006b, El Alto de las Guitarras. La técnica en las manifestaciones rupestres. En: Sian, A. 1, $\mathrm{N}^{\circ} 17$.

Campana C. 2013, Una serpiente y una historia del agua. Trujillo: Universidad Privada Antenor Orrego.

Castillo D. 2000, El Alto de la Guitarra, un misterio sobre rocas. En: La Industria suplemento dominical, 27 de febrero, pp. 6-7.

Castillo D. y M. Barrau, 2014. Arte rupestre en el Alto de la Guitarra: paraíso de cazadores, calendario agrícola, mitología y ritual en la costa norte peruana. En: Conchopata V. 4, pp. 309-334.

Castillo D. y M. Barrau, 2016 Avances en el inventario de sitios con arte rupestre en la cuenca del río Virú. En: Arkinka, V. 252 pp. 100-111.

Oficina Nacional de Evaluación de los Recursos Naturales 1973 Inventario, evaluación y uso racional de los recursos naturales de la costa. Cuenca del río Moche, Lima.

Rostoworowski, M. 1981, Recursos naturales renovables y pesca, siglos XVI y XVII. Lima: Instituto de Estudios Peruanos.

Rostworowski, M. 2007, Estructuras andinas del poder.Ideología religiosa y política. Lima: IEP

Silverman, H. 1988, Cahuachi: non-urban cultural complexity on the outh coast of Peru. En: Journal of Field Archaeology, V. 15, N 4, pp. 403-430.

Taylor, G. 2008. Ritos y tradiciones de Huarochirí. Lima: IFEA 